\title{
Decision support system for technological maintenance of seeding machines
}

\author{
Vasiliy Kapustin ${ }^{1}$, Kirill Nemtinov ${ }^{1}$, Yulia Nemtinova ${ }^{1,2}$, and Vladimir Nemtinov ${ }^{1, *}$ \\ ${ }^{1}$ Tambov State Technical University, 392000, Sovetskaya st., 106, Tambov, Russia \\ ${ }^{2}$ Tambov State University named after G.R. Derzhavin, 392000, Internatsionalnaya st., 33, Tambov, \\ Russia
}

\begin{abstract}
In this paper, we consider information support for decisionmaking in technological maintenance of agricultural machines before and during technological operations that guarantee their high quality and contribute to improving production efficiency: increasing crop yields up to $30 \%$; increasing shift productivity by $10 \ldots 12 \%$; reducing fuel consumption per unit of work performed by 5 ... 8\%; reducing downtime due to technical reasons up to $20 \%$. The authors have developed an information and logical model for decision support that allows them to select the best option for carrying out technological maintenance of agricultural machines depending on the current state of machine's components and mechanisms and specified agro-technical requirements. To implement the information and logic model, the software environment of the CLIPS expert system is used, including a full-fledged objectoriented COOL language. The model was tested on the example of technological maintenance of seeding machines.
\end{abstract}

\section{Introduction}

In the process of technological operations, each agricultural machine and unit is exposed to a large number of changing factors: variable load, which depends on sowing width, soil (plants) type and moisture, hardness and resistivity of soil; movement speed; crop yield; sowing rates for seeds and fertilizers; environmental conditions - temperature, humidity and density of soil, presence of abrasive particles in the air. These factors lead to wear of friction surfaces: bushings, bearings, chains, belts, adjusting bolts, springs; blunting of the blades, which results in broken adjustments, reduced quality of work performed, increased fuel consumption, increased traction resistance (load). Therefore, components, mechanisms, or a machine as a whole may fail prematurely or create an emergency state [1 - 3].

The quality of field work can decrease not only by violated adjustment of some node, unit or machine, but also by displacing of working bodies, bending of the frame beams, changing of the length of the adjusting rods, linkage, etc. In this case the question of adjusting mechanisms of the machine and configure the unit as a whole by the specified modes of operation becomes crucial. Adjustment of working bodies, components and mechanisms of the machine changes their location parameters within the limits determined

*Corresponding author: nemtinov@mail.gaps.tstu.ru 
by technical and agro-technical requirements to create normal (accident-free) working conditions. These requirements determine operational tolerance of each adjustment parameter of a working body, unit and mechanism of a machine, tool or unit as a whole. Adjustment of working bodies, units, and mechanisms of machines is divided into technical and technological [4 - 5].

Technical adjustment is carried out in accordance with technical requirements, whereas technological - in accordance with agro-technical requirements for the machine. Technical adjustment depends mainly on the design, material and technical conditions (wear) of the unit, mechanism or machine and can be carried out at any time of the year: during repair of agricultural machines, installation or removal from the storage, preparation of equipment to be used for its intended purpose. Technological adjustment depends on technology of cultivation and harvesting of agricultural crops, type of cultivated crops and soil and climatic conditions. This type of adjustment is carried out right before going to the field, when the crop, soil type and agro-technical requirements are known, and when appropriate devices and tools are available - directly in the field.

Studies conducted in a number of regions of the country revealed the following reasons of poor quality of field work [2, 3, 6]:

- agricultural machinery is becoming more and more complex, and methods and means for checking its technical condition and adjusting it to optimal operating modes remain primitive. There are also no uniform rules for checking and configuring machines;

- agricultural machines are produced with insufficient reliability, a large percentage of defects and a low coefficient of adaptability to adjustments;

- about 53\% of machine operators do not know how to adjust and configure agricultural machines for optimal operation modes;

- performers are not responsible for bad work and do not receive remuneration for good quality of field work.

It should be noted, that no matter how advanced the automated machines are, adjustment and related operations, as well as control over these parameters will always be required. This is due firstly, to wear and tear of working bodies, secondly, to changing soil and climate conditions (different zones of the country), and thirdly, to the difference and improvement of crops cultivation technologies. Based on this, improving the quality of all mechanized work in cultivation and processing of agricultural crops is possible only if technological maintenance of the equipment is carried out in a timely manner. Therefore, engineering service specialists need not only deep knowledge in design and theory of working processes of agricultural machines, but also the ability to perform adjustment depending on the properties and condition of soil, technical condition, wear of parts, components and mechanisms of machines, taking into account agricultural requirements.

In this regard, the current paper is devoted to development of an information and logical model (ILM) for decision support during technological maintenance of agricultural machines before and during technological operations.

\section{Technical requirements for seeding and planting machines}

In order to maintain high-quality and timely execution of all field work, careful preparation of agricultural machinery is required. If these works are carried out at the optimum time for well-adjusted machines in accordance with rules of farming, this has a positive impact on yield, quality of grain, root crops, vegetables and other agricultural products. Poorly performed field work is an incorrigible defect in most cases, i.e. seeds sown at a smaller depths than those specified by agro-technical requirements cannot be collected and re-sown to the specified depth, since the agro-technical terms of sowing this crop have ended; plants cut during row-to-row processing will not be able to grow and yield a crop; rotten hay will 
not be nutritious. Especially high losses occur from poor-quality of harvesting. For example, damaged grains, roots and vegetables lose their nutritional properties to a large extent and rot faster, and the grain lost during harvesting by the combine can not be collected again.

To create a list of measures for technological maintenance of agricultural machines, it is necessary to follow the main documents regulating inspection, alignment and adjustment of agricultural machines and tools: operating instructions of manufacturers, technical specifications for individual machines.

The criterion for evaluating the quality of adjustment for agricultural machines and units is compliance with agro-technical requirements. As an example, we present a number of requirements for seeding and planting machines:

- row width or the distance between adjacent disks in a row for the seed-fertilizer seeder SZ-3,6, SZP-3,6, SZ-5,4 shall be $300 \pm 10 \mathrm{~mm}$, and between rows $-350 \pm 10 \mathrm{~mm}$. Cutting edge thickness of disks $-0.5 \mathrm{~mm}$, cutting clearance between the blades of the disk openers should not exceed $1.5 \mathrm{~mm}$;

- springs on the rods must be compressed to the same length, except for the coulters that move along the track of the tractor engine;

- when the drive chain is pressed with a force of $100 \mathrm{~N}$, its deflection should be 10 ... 12 $\mathrm{mm}$; the chain misalignment should not exceed $2 \mathrm{~mm}$;

- when the rod is fully extended (the distance between cylinder pins is $700 \mathrm{~mm}$ ), the transport clearance (distance from the soil surface to the lower edge of the coulters) must be $190 \mathrm{~mm}$;

- force on the lever regulating seeding at axial displacement of the shaft must not exceed $98 \mathrm{~N}$. The case of a seed meters should fit the bottom of the box with no gap. Local clearances should not exceed $0.8 \mathrm{~mm}$;

- indicators of seeding regulators at complete overlap of seeding holes with couplings must coincide with the zero division of the scale or deviate by no more than one division;

- outreach deviation of the coil's working length for seeding devices should not exceed $0.5 \mathrm{~mm}$. The gap between the scrapper and the disks - no more than $2 \mathrm{~mm}$;

- when installing the valve shaft lever in the uppermost position, the gap between the coupling edge and the valve for grain seeding machines should not exceed $0.5 \mathrm{~mm}$ and for a seed-fertilizer seeders $-1 \mathrm{~mm}$.

- tire pressure of the SZ-3,6 seeder wheels should be $0.16 \ldots 0.2 \mathrm{MPa}$; SZP-3,6- $0.2 \ldots$ $0.25 \mathrm{MPa}$. Axial backlash of wheels on rolling bearings - no more than $0.5 \mathrm{~mm}$.

- when lifting and lowering, the coulters must move in a plane that coincides with the symmetry plane of the rods; deviation must not exceed $8 \mathrm{~mm}$;

- ....

Failure to comply with these and other requirements leads to a decrease in the quality of field work and productivity of aggregates.

\section{Development of an information and logical model for decision support}

In the general form, an ILM for decision support during technological maintenance of agricultural machines before and during technological operations is a combination of data sets and relationships between them in the form of rules. A separate production rule contained in the knowledge base consists of two parts [7 - 11]: antecedent and consequent. An antecedent is a rule premise (conditional part) and consists of elementary sentences connected by logical strings AND, OR. A consequent (conclusion) includes one or more sentences that express either a certain fact or an indication of a certain action to be performed. 
Thus, an ILM can be represented by the following tuple:

$\mathrm{M}=\left(d_{1}, \ldots, d_{i}, \ldots, d_{N}, p_{1}, \ldots, p_{j}, \ldots, p_{S}\right)$,

where M - ILM operator, $d_{1}, \ldots, d_{N}$ - sets of ILM data, $p_{1}, \ldots, p_{S}$ - set of rules.

In turn, the rules included in the model are built according to the type : if ... (conditions are met), then ... (implementation of the consequence), in a formalized form , are described as follows:

$$
p^{\kappa}:\left\{\text { if }\left(\left(d_{1}^{\kappa^{\prime}} \mathrm{A}_{1} z_{1}^{\kappa^{\prime}}\right) \Lambda_{1}\left(d_{2}^{\kappa^{\prime}} \mathrm{A}_{2} z_{2}^{\kappa^{\prime}}\right) \Lambda_{2} \ldots \Lambda_{n-1}\left(d_{n}^{\kappa^{\prime}} \mathrm{A}_{n} z_{n}^{\kappa^{\prime}}\right)\right) \text { then }\left(d_{1 m}^{\kappa^{\prime \prime}} \mathrm{A}_{1}^{\prime} z_{1 M}^{\kappa}{ }^{\prime \prime}\right)\right\} \text {, }
$$

where if - designation of the terms "if", then - designation of the consequence "then", $\mathrm{A}_{1}^{\prime}, \mathrm{A}_{i} \in\{=,>, \geq,<, \leq, \neq, \neg\}, i=\overline{1, n}$ - arithmetic operator, $\Lambda_{i} \in\{\wedge, \vee\}$ - logical operator, $d_{s}^{\prime}, d_{1 m}{ }^{\prime \prime}$ - model's input and output data correspondingly, $Z^{\kappa^{\prime}}=\left\{z_{1}^{\kappa^{\prime}}, \ldots, z_{n}^{\kappa^{\prime}}\right\}$ - values of the antecedent $d_{s}{ }^{\prime}, z_{1}^{k^{\prime \prime}} \in\left\{z_{11}^{k}, \ldots, z_{1 M}^{k}\right\}$ - the value of the consequent $d_{1 k}, n$ - number of conditions, $\kappa$ - rule index.

Let's consider decision rules for forming the list of measures for technological maintenance of agricultural machines before and during technological operations. They are collected by specialists in application-specific data (experts) [6, 10 - 14] and authors in contacts with specialists in maintenance of agricultural machines.

Currently, the database contains more than 200 production rules, which can be used to create the optimal list of measures for technological maintenance of agricultural machines for their specific current state and specified agro-technical requirements.

The following is an example of rules for sowing equipment:

a) rules for the selecting the measures for grain seeders SZ-3,6; SZP-3,6:

- if "quality indicator of the technological operation" = "there is no uniformity in the stroke depth of working bodies", then "means of regulation" = "pins, holes in the rods" and "method of adjustment" = "change in the force of pressure springs";

- if "quality indicator of the technological operation" = "invalid width of the guess row spacing", then "control device" = "trailer device, hitch bar" and "adjustment method" = "change the placement of working bodies»;

- if "quality indicator of the technological operation" = "invalid row spacing", then "control means" = "main beam, mounting unit of working bodies" and "adjustment method" = "change the placement of working bodies»;

- if "quality indicator of the technological operation" = "seeding rate of seeds and mineral fertilizers is not provided", then "control means"= "lever for turning the valve roller" and "adjustment method" = "change the gap between the valve and the coupling rib»;

- if "quality indicator of the technological operation" = "seeding rate is not provided", then "control means" = "the lever for moving the shaft of the seeding devices" and "the adjustment method" = "change the position of the coils»;

- ...;

b) rules for selecting adjustment measures for the SUPN-8 seeder:

- if ("quality indicator of technological operations" = "no uniform stroke depth of the working bodies", then "tool of regulation" = "adjustment screw, which moves the mechanism with working bodies up or down" and "method of adjustment" = "change the position of the working bodies relative to the supporting wheels or frame»; 
if ("quality indicator of process operation" = "seeding rate is not provided", then "control device" = "disks with different number and diameter of holes" and "adjustment method" = "replacement of seeding disks»;

In order to implement the information and logic model, the software environment of the CLIPS expert system is used, which includes a full-fledged object-oriented COOL language.

\section{Results and discussion}

As a result of the conducted research, the authors developed an information and logical model for decision-making support during technological maintenance of agricultural machines before and during technological operations, which allows choosing the best measures depending on the current state of nodes and mechanisms of the machine and specified agro-technical requirements. Its testing performed during the maintenance of seeding machines, helped to increase production efficiency, i.e.: increase the yield of agricultural crops to 30\%; increase shift productivity by $10 \ldots 12 \%$; reduce fuel consumption per unit of work performed by 5 ... 8\%; reduce downtime for technical reasons up to $20 \%$.

\section{References}

1. A. Apazhev, V. Smelik, Y. Shekikhachev, L. Hazhmetov, Combined unit for preparation of soil for sowing grain crops, Engineering for Rural Development, v.18, pp. 192-198 (2019)

2. P.Oleinik, N. Cherednichenko, Organization of demolition works during production buildings reconstruction, IOP Conference Series: Earth and Environmental Science, v. 403(1), 012189 (2019)

3. I. Vorotnikov, M. Gutuev, K. Petrov, O. Esin, Concept of regional technical service development, Espacios, v. 38(23), 22 (2017)

4. D.E. Houssaini, S. Khriji,K. Besbes, O. Kanoun, Wireless sensor networks in agricultural applications, Energy Harvesting for Wireless Sensor Networks: Technology, Components and System Design, pp. 323-342 (2018)

5. V.A. Nemtinov, Y.V. Nemtinova, An approach to regulating the relationships between environmental users, Journal of Computer and Systems Sciences International v. 43(5), pp. 800-804 (2004)

6. O.V. Myalo, S.P. Prokopov, V.V. Myalo, A.S. Soyunov, E.V. Demchuk, Material and technical support of the enterprises of the agro-industrial complex of the Omsk region management and certification of the technical component of the production processes in crop production, IOP Conference Series: Materials Science and Engineering, v. 582(1), 012028 (2019)

7. K. Nemtinov, A. Eruslanov, Y. Nemtinova Nemtinov, Rationale construction of individual elements of technological complex, MATEC Web of Conferences, v. 224, 02036 (2018)

8. V.A. Nemtinov, Yu.V. Nemtinova, On an approach to designing a decision making system for state environmental examination, Journal of Computer and Systems Sciences International. v. 44(3), pp. 389-398 (2005)

9. V.G. Mokrozub, V.A. Nemtinov, An Approach to Smart Information Support of Decision-making in the Design of Chemical Equipment, Chemical and petroleum engineering, 51(7-8), pp. 31-35 (2015) 
10. V.G. Mokrozub, V.A. Nemtinov A.V. Mokrozub, Procedural model for designing multiproduct chemical plants, Chemical and Petroleum Engineering. v. 53(5-6), pp. 326-331 (2017)

11. V.A. Nemtinov, A.N. Zazulya, V.P. Kapustin, Yu.V. Nemtinov, Analysis of decisionmaking options in complex technical system design, Journal of Physics: Conf. Series. v. 1278(1) 012018 (2019)

12. A.B. Borisenko, S.V. Karpushkin, Hierarchy of processing equipment configuration design problems for multiproduct chemical plants, J. of Computer and Systems Sci. Int. v. 53(3), pp. 410-419 (2004)

13. V. Alekseev, D. Lakomov, A. Shishkin, G.Al. Maamari and M. Nasraoui, Simulation images of external objects in a virtual simulator for training human-machine systems operators, Jornal of Physics: Conference Series, v. 1278012032 (2019)

14. O. Krol, V. Sokolov, Modelling of spindle nodes for machining Jornal of Physics: Conference Series, v. 1084012007 (2018) 